\title{
Contexualising the tool development process through a knowledge brokering approach: The case of climate change adaptation and agriculture
}

\author{
Camilla Adelle* \\ Centre for the Study of Governance Innovation, Department of Political Sciences, University of Pretoria, \\ Pretoria, South Africa \\ Tyndall Centre for Climate Change Research, School of Environmental Sciences, University of East Anglia, \\ Norwich, UK
}

*Corresponding author: Camilla.adelle@up.ac.za Tel: +27 (0)83 2604703

\begin{abstract}
This article applies a 'knowledge brokering' approach to contextualise the development of an integrated computer modelling tool into the real world policy context of adaptation of agriculture to climate change at the EU level. In particular, the article tests a number of knowledge brokering strategies described and theorized in the literature, but seldom empirically tested. The article finds that while the policy context can be used to identify a theoretically informed knowledge brokering strategy, in practice a strategy's 'success' is more informed by practical considerations, such as whether the tool development process is knowledge or demand driven. In addition, in practice the knowledge brokering process is found to be dynamic and messy, which is not always apparent in the literature. The article goes on to question the perception that there is always a need (or a desire) to bridge the gap between researchers and policy makers in the tool development process. Rather than a problem of design and communication, the science policy interface may be characterised more by a high level of competition between researchers and research organisations to have their tool legitimised by its use in the policy making process.
\end{abstract}

\section{1) Introduction}

Farmers have always adapted to changes in the weather. However, the challenge now is to adapt within comparatively short periods of time to potentially extreme climatic impacts (AEA 2007). A European Commission White Paper 'Adapting to Climate Change' highlights adaptation in agriculture as a key policy challenge in future and opens up debate on possible actions (European Commission 2009a,b). However, in order to devise and assess these potential policy options the European Commission requires detailed information and scientific evidence that reflects the diversity of regional and local agriculture (European Commission, 2009a). Agricultural research that considers complex cross-cutting policy problems, such as climate change adaptation, has a history of employing computer modelling (van Ittersum et al., 2008). Such approaches are capable of not only working cross-scales by bridging the micro (farm or local regional) and macro (market or sector) levels but they also link different disciplinary perspectives so that social, environmental and economic impacts can be considered alongside each other (van Ittersum et al. 2008). The variety in computer-based models or tools generated to aid decision making in this and other policy fields, however, has led to complaints about their poor up take as well a lively debate about how to better 
design or develop these tools so that they are of greater use to policy makers (Nilsson et al 2008; Sterk et al. 2009a). The implicit assumption here is that the increased uptake and use of these models, especially for complex cross-cutting problems, will lead to more informed and ultimately 'better' decision making. This linear-rational view of tool use has led to a perception amongst some researchers, especially in the field of policy level impact assessment, that there is a need to 'bridge the gap' between researchers and policy makers in a way that leads to enhanced tool use in policy making (Nilsson et al 2008).

Various 'success factors' for the uptake by policy makers of agricultural modelling tools, as well as the knowledge that they generate, have been specified in the literature on tool development, including: the need for appropriate timing; the use of graphical interfaces; and greater transparency (Sterk et al. 2009a). However, Sterk et al. (2011) suggest tool developers go further and rethink how model development and application should be arranged. They suggest that 'equal attention should be paid to the requirements for the model development and the embedding of the work in a given/intended societal context' (p. 315). One way to embed the tool development in a societal context, or 'contextualise' it, is by involving policy makers in tool development process (e.g. Bäcklund et al. 2010; Sterk et al. 2011). The general argument here is that the more interaction these actors have from an early stage of tool development, the greater the ultimate impact of the modelling in policy making (Sterk et al. 2011). However, few attempts to test and elaborate this argument through real life examples of tool development (but see Bäcklund et al. 2010) have been reported and even fewer grounded in the literature and techniques of policy sciences.

This article aims to address this gap in the literature by applying a 'knowledge brokering' approach to contextualise the development of an integrated computer modelling tool. According to van Kammen et al (2006: 608), "[The focus of knowledge brokering] is not on transferring of the result of research, but on organising the interactive process between the producers and users of knowledge so that they can coproduce feasible and research-informed policy options". The article gives an empirical account of the attempts of a knowledge broker (the author) to help embed the development of an integrated computer model, which links four existing bio-physical and economic tools in the area of agriculture and land use, to a real world policy problem of the adaptation of agriculture to climate change. In particular, the article attempts to explore and test out a number of strategies and techniques described and theorized, but seldom empirically tested, in the knowledge brokering literature (e.g. Michaels 2009; Sheate and Partidario 2010; Ward et al. 2011). This leads to three specific research questions to help gauge how useful a knowledge brokering approach is for contextualising and ultimately reorganizing the tool development process: Which knowledge brokering strategies and techniques work best to embed the tool development process in this particular societal context? Are these the same strategies anticipated in the knowledge brokering literature? What are the main barriers to employing a knowledge brokering approach in the tool development process?

The structure of the rest of the article proceeds as follows. The next section sets out some of the key contextual characteristics of this real world case study or 'case' and which lead to a theoretically informed choice of knowledge brokering strategies to be applied (and tested). The following section then describes the practical steps that took place in the knowledge brokering of the tool development process. The more detailed and specialised aspects of the tool development are the 
focus of other, more technical, publications and will not be discussed here. The fourth section of the article then reflects on how useful the knowledge brokering approach was in reorganising the tool development process by considering each of the research questions in turn. The concluding section attempts to draw wider lessons from this single case both for the literature on knowledge brokering and tool development.

\section{2) The 'case' study: Context, strategies and methods}

In a seminal article linking the literature on knowledge brokering to public policy literature on decision making, Michaels (2009) reviews several decision-aiding frameworks from the public policy literature and identifies knowledge brokering strategies which are 'fitting and constructive for each of the different policy problems or settings identified through the frameworks' (Michaels 2009, p. 1008). Each framework has a different emphasis and is used here to make a theoretically informed choice of knowledge brokering strategy to be employed and tested in this case.

\section{1) Case characteristics}

According to the framework of decision modes set out by Lindquist (2001) and reiterated by Michaels (2009), the case can be characterised as an 'emergent decision regime'. This is where a policy base (or network) has not (yet) emerged and so the policy area is wide open to the development of a broad vision. This decision mode is further characterised by Lindquist (2001) as containing a relatively small number of actors at the outset with the detail of inquiry at a relatively broad perspective and detailed work proceeding only on selective issues. The EU's Common Agricultural Policy (CAP), in general, is a crowded and politically contested area of policy making that is characterised by a large number of interested actors (Daugberg and Swinbank 2009). However, potential policy measures to address the adaptation of agriculture to climate change are not yet part of the CAP and the issue of the adaptation of agriculture to climate change has only recently emerged over the political horizon of DG Agriculture (European Commission 2009a; 2009b). It is therefore a less politically fraught and crowded policy space than reforms of the CAP. Nevertheless, a number of exploratory studies - including those using computer modelling - had already been commissioned by the European Commission through its 'habitual routes' of information gathering (e.g. AEA 2007; Iglesia et al 2009; Donatelli et al 2012). DG Agriculture has developed a large number of tried and tested researchers and experts upon which it can call, many of which are closely linked to the Commission. In addition, various organisations have been set up within the Commission to facilitate the use of models and the information that they provide into decision making: For example, the Joint Research Council (JRC) and the Institute for Prospective Technological Studies (IPTS) have been running models for DG Agriculture for over a decade.

A second important characteristic is the place the case occupies in the 'sense-making framework' described by Kurtz and Snowden (2003). This framework seeks to understand how people make sense of what they experience so they can act upon it. According to the framework, this case can be placed within the 'unordered domain of complex relationships' where 'simple interactions among subunits generate the rich collective dynamical behaviour of complexity' which, in part at least, defy categorization or analysis (Rickles et al. 2007 in Michaels 2009, p. 1006). The enormous complexity governing the interactions between the processes through which climate change could potentially impact agriculture and the uncertainty associated with modelling them make it extremely difficult to 
make reliably quantify the aggregate impacts on a global or even European scale (Donatelli et al. 2012). In this case an interdisciplinary team of modellers attempted to link four existing bio-physical and economic tools in order to capture a greater number of possible processes and interactions between these processes than possible when using each of these models individually.

Third, the policy problem can be described as 'unstructured'. According to a typology of policy problems constructed by Turnhout et al. (2007), an unstructured problem is characterised by the lack of consensus on goals and how to achieve them. Developing policy in these areas is consequently a learning process requiring intensive interaction among those holding conflicting perspectives and interests (Turnhout et al. 2007). The policy problem in this case (i.e. how can agriculture best be governed to adapt to future climate change) is characterised by a high degree of scientific uncertainty and complexity, not only in terms of the likely changes in climate and possible impacts on agriculture across Europe (see above), but also in terms of how - or even whether - it might be necessary to make policy changes to help European agriculture to adapt to these impacts. Therefore, there is little consensus on what the specific policy goals or instruments should be.

\section{2) Selecting a Knowledge Brokering Strategy}

Michaels (2009) argues that these kinds of characteristics of a policy problem and setting can be used to chose which of the six knowledge brokering strategies identified from the knowledge brokering literature should most usefully be employed (see Table 1). These strategies range from the relatively simple strategies for structured problems and the ordered domain of knowable causes and effects to the more complex and resource intensive strategies for unstructured problems in the unordered domain. The most complex strategies are suitable for emergent decision regimes where the key role of the knowledge broker is to facilitate consultation, build social capital (e.g. trust and shared values) and to help both policy makers and researchers gain multiple perspectives. Michaels claims that identifying where one intends to contribute to the science policy interface and choosing the most appropriate

Table 1. Six Knowledge Brokering Strategies (Source: Micheals 2009)

\begin{tabular}{|c|c|c|}
\hline Strategy & Intent & Example of brokering techniques \\
\hline Inform & Disseminate content & Fact sheets, web sites \\
\hline Consult & $\begin{array}{l}\text { Seeks out known experts to advise on problem } \\
\text { delineated by party seeking counsel }\end{array}$ & Meetings, solicited assessments \\
\hline Matchmake & $\begin{array}{l}\text { Identify what expertise is needed, who can provide } \\
\text { it and the best ways to make the connections }\end{array}$ & $\begin{array}{l}\text { Introduce people to each other } \\
\text { who would not otherwise meet }\end{array}$ \\
\hline Engage & $\begin{array}{l}\text { One party frames the discussion through terms of } \\
\text { reference and for the life of the required decision } \\
\text { making process, involves other parties in } \\
\text { substantive aspects of the problem on an as } \\
\text { needed basis }\end{array}$ & $\begin{array}{l}\text { Royal commissions; Technical } \\
\text { committees, Secondments }\end{array}$ \\
\hline Collaborate & $\begin{array}{l}\text { Parties jointly frame the process of interaction and } \\
\text { negotiate substance to address a distinct policy } \\
\text { problem }\end{array}$ & Joint agreement \\
\hline Build capacity & $\begin{array}{l}\text { Parties jointly frame process of interaction and } \\
\text { negotiate substance with intent of addressing } \\
\text { multiple dimensions of a policy problem while } \\
\text { considering what can be learned from doing so that } \\
\text { is applicable to implications of the issue, future } \\
\text { scenarios and related concerns }\end{array}$ & $\begin{array}{l}\text { Co-management; Joint fact finding; } \\
\text { co-production of knowledge }\end{array}$ \\
\hline
\end{tabular}


strategy is important: On the one hand it is not advisable to use a more labour intensive strategy than necessary and on the other, employing an insufficiently sophisticated one is likely to be frustrating and to 'result in potential contributions of expertise not being incorporated into decision making' (Michaels 2009, p. 1008).

These theoretically informed expectations about the role of knowledge brokering strategies in different contexts led to the initial choice of a relatively elaborate and resource intensive strategy to be employed in this case. This was not entirely a clear-cut choice: While the unstructured nature of the policy problem and its position in the unordered domain, indicated at least a mid-level knowledge brokering strategy (i.e. 'engaging'), the emergent decision regime mode indicated that it was necessary to employ the most elaborate strategy (i.e. building capacity). However, all of these indicated strategies are in the medium to high side of the spectrum of strategies and therefore, in the end a strategy of 'collaboration' was selected to be employed. Michaels (2009, p. 998) describes 'collaboration' as a strategy which 'involves all the participants in jointly framing the process of how they interact with each other and to negotiate how to scope the problem to be addressed.' This strategy therefore implies relatively high effort and investment of resources from both 'policy makers' and 'researchers' (see below) and it was the role of the knowledge broker to facilitate and encourage this high level of interaction.

\section{3) The knowledge broker - roles and methods}

Ward et al (2009, p268) argue that '[k]nowledge brokerage can reside in individuals, organisations or structures'. In this case, the 'knowledge broker' role was mainly played by a social scientist (i.e. the author of this article), who acted as a broker or a 'stepping stone' (Sterk 2009b) between a group of computer modellers - the 'researchers' - and key officials in DG Agriculture and Rural Development (DG agriculture) within the European Commission - the 'policy makers'. The distinction between 'researchers' and 'policy makers' is an artificial one and in reality the boundary between science and politics is commonly rather fuzzy: Within DG Agriculture, policy officials are often technically trained with significant experience of using economic models before entering the Commission.

The knowledge brokering process took place between the beginning of September 2010 and the end of April 2013 (see Table 1). It included several meetings and other interactions between the policy makers and the researchers facilitated by the knowledge broker. These are described in the next section of this article. However, the knowledge broker had a second role, namely to observe the knowledge exchange between the two parties: Embedded in the team of researchers, the knowledge broker was ideally positioned as a participant observer. As a consequence the broker was privy to email correspondence and internal documents, attended meetings and was able to interact with the 'researchers' through conversations and informal interviews. This method of data collection was to some extent limited by the artificially-bounded nature of the observations and the reliance on the knowledge broker's representation of the knowledge exchange process (Ward et al., 2011). In particular, the knowledge broker was not privy in the same way to the perspective of the policy makers. In addition, the location of the knowledge broker within the team of researchers to some extent creates a situation where the broker could be perceived as being 'on the side' of the researchers rather than entirely neutral. 


\section{3) Brokering the Tool Development Process}

The starting point for the tool development exercise was the researchers' intention to 'improve' their biophysical tools and economic models in the field of agriculture, ${ }^{1}$ by linking them so that they could generate more integrated information than if the tools were applied individually. These tools had been developed in previous EU funded research projects that the researchers had been involved in namely, NitroEurope, SEAMLESS and Agri-Adapt. The tool development exercise was to be carried out as part of the EU funded LIAISE (Linking Impact Assessment Instruments with Sustainability Expertise) 'network of excellence'. The main purpose of LIAISE was to identify and exploit opportunities to bridge the gap between researchers (i.e. tool developers) and policy makers (i.e. tool users) in a way that leads to enhanced tool use in policy making (LIAISE no date). The tool development process was carried out in four phases described below.

\section{1) Formulation Phase}

In the first 'Formulation Phase' the role of the knowledge broker in practice was to 'match-make' researchers and policy makers who would not otherwise be connected (Michaels 2009) and thereby help the researchers locate their tool development process in a real world policy context. Although some of the researchers had relatively close contacts within DG Agriculture on specific issues from their previous research projects, they were not keen to personally call upon these contacts at this stage: The researchers felt that it was necessary to first have credible and tangible ideas to present to policy makers so as not to risk promising more than they could deliver. In the autumn of 2010 the knowledge broker met with various officials in the European Commission in order to identify potential policy areas that might be of mutual interest to both policy makers and researchers (see Table 2). During these exchanges, the question of how the CAP could help European agriculture adapt to future climate change was identified as one such area. Consequently, the researchers developed their technical ideas into a short proposal embedding their planned integrated model development into this 'real world' policy context.

Table 2: Chronology of main knowledge brokering activities

\begin{tabular}{|l|l|}
\hline Time Period/Phase & Knowledge Brokering Activity \\
\hline Formulation Phase & Initial contact between 'policy makers' and 'researchers' \\
\hline Autumn 2010: & Researchers draft initial research idea \\
\hline Spring 2011: & Researchers further refine proposal \\
\hline Spring 2011 -2012: & $\begin{array}{l}\text { First meeting between researchers and policy makers in the offices of DG } \\
\text { Agriculture (Meeting 1) }\end{array}$ \\
\hline Scoping and Planning Phase \\
\hline March 2012: & Follow up internal meeting amongst researchers (Meeting 2) \\
\hline May 2012 & $\begin{array}{l}\text { Smaller Teleconference between researchers and policy makers } \\
\text { (Meeting 3) }\end{array}$ \\
\hline June 2012: & First stage of modelling \\
\hline Instrumental Phase & $\begin{array}{l}\text { Second meeting between researchers and policy makers in the offices of } \\
\text { June 2012 - March 2013 Agriculture (Meeting 4) }\end{array}$ \\
\hline Iterative Learning Phase
\end{tabular}


Once this initial proposal had been drafted, however, the researchers struggled to go forwards due to a 'chicken and egg' problem: To make progress (e.g. develop research questions) the researchers felt that they needed to further embed their work in the chosen policy context (e.g. develop policy questions) but they did not feel comfortable in having direct contact with policy makers to discuss how to do this until the proposal was further developed (i.e. they had developed research questions). The level of interaction between researchers and policy makers therefore remained low. After several months of discussion, facilitated in part by the knowledge broker, the researchers decided - not least on the basis of lapsing research timetables - to continue with the technical work without additional - let alone iterative - input from the policy makers.

\section{2) Scoping and Planning Phase}

In the next 'Scoping and Planning Phase' the knowledge broker helped the researchers to frame their discussion with the policy makers in a way that was intended to most actively involve these officials in the substantive aspects of the problem. This 'engaging' strategy was pursued through relatively simple techniques, such as email and telephone exchanges, face-to-face and teleconference meetings, as well as relaying and repackaging information between both parties. In March 2012, the knowledge broker set up a half-day meeting between six researchers and eight policy makers in DG Agriculture in Brussels (Meeting 1 - see Table 1). This included, but went beyond, those officials already approached in the Formulation Phase. Prior to the meeting the knowledge broker prepared a two-page background document for the policy makers to present the tool development exercise as a whole, the knowledge brokerage approach, as well as the specific issues on which the researchers sought feedback. The first half of the meeting was designed to illicit an open-ended type of information from both the researchers and policy makers through a more 'collaborative' knowledge brokering strategy. An initial round table session gave each participant an opportunity to introduce themselves and their experience in the field as well as set out their expectations of the tool development exercise. The policy makers stressed that they did not want to make any formal commitment on behalf of DG Agriculture but would participated on a personal basis. These introductions were followed by a 'group mapping' exercise in which each policy maker and researcher briefly presented to the group their ideas for policy and research questions for the tool development exercise. These ideas were then grouped together in similar clusters (identified as coming from either researchers or policy makers). In the second half of the meeting, the knowledge broker again adopted a more 'engaging' strategy to help the researchers presented their proposal to integrate their models and gain substantive feedback from the policy makers on specific parameters (e.g. on issues concerning the impact indicators, scales and geographical scope of the integrated model).

The technical and more open input from the policy makers gathered from both parts of this meeting was considered in detail by the researchers in an internal meeting soon after (Meeting 2 - see Table 1). In the end, the researchers were more able to identify common ground between themselves and the policy makers than to adjust their proposal to meet the needs of the policy makers: Requests by the policy makers for the consideration of, for example, life cycle analysis, carbon leakage, and shorter time horizons were considered 'outside of the scope' of the modelling development process while other issues raised by the policy makers, such as the role of changing technology and the inclusion of certain scales of analysis were considered by the researchers as 'part of the modelling approach'. 
The knowledge broker then set up a short (one hour) teleconference (Meeting 3 - see Table 1 ) between a smaller number of researchers (two) and policy makers (three). All of the policy makers had been to Meeting 1 and had been identified by the researchers and policy makers as particularly important to the tool development process) in which outstanding technical issues were discussed and feedback obtained. A policy maker also informed the researchers of recently commission research commissioned in the policy area (e.g. Donatelli et al 2012) in order for the researchers to 'add value' to the existing information. However, requests for more active input to the tool development process (e.g. checking and adding to the written documents) were not taken up by the policy makers. To some extent this was due to both the busy schedules of the policy makers as well as their reluctance (due to political sensitivities) in adjusting the policy scenarios according to the likely (but not yet politically agreed) outcomes of the ongoing CAP reforms. The lack of active input into the tool development process at this point appeared to confirm the view of some of the researchers that 'we should simply forget the idea to have a lot of interaction' with policy makers.

\section{3) Instrumental Phase}

Once these key inputs and scope of the exercise had been agreed by the policy makers, the technical task of linking the individual models was undertaken by the researchers in relative isolation. According to the timetable agreed from Meeting 1, the first 'basic' stage of technical model development work was anticipated to be completed by December 2012 and then to be followed by a further secondary stage of model improvement. Due to the long time horizon of the tool development process, this article reports only on the first stage of tool development.

\section{4) Iterative Learning Phase}

Another face-to-face meeting between the researchers and policy makers was arranged by the knowledge broker in March 2013 (Meeting 4 - see Table 1). This meeting was delayed for several months partly as the researchers were reluctant to present what they perceived to be unfinished, and therefore provisional, results: more time it was argued could lead to better - more detailed and finessed - results. The meeting was attended by two policy makers and four researchers and so was smaller than the first face-to-face meeting (Meeting 1) and, similar to Meeting 3, was highly focused and technical. The discussions were directed towards updating the policy makers on progress from the first stage of tool development as well as obtaining specific technical feedback for the second stage of tool improvement. The results of this first stage of modelling was received positively by the policy makers and discussed at a highly technical level. The policy makers interacting with the researchers by this point in the tool development process were technically trained modellers and economists who themselves fulfilled a knowledge brokerage role within the Commission. In contrast, the higher level policy makers that were also present in Meeting 1 were no longer directly engaged in the exercise. These more generalist policy makers had performed a slightly different role to the lower level policy makers: they had identified priority areas and signalled interest (if not commitment) to embarking on the tool development exercise. 


\section{4) Reflecting on the knowledge brokering approach}

\section{1) Which knowledge brokering strategies and techniques worked best to embed the tool development process in this societal context?}

Although only one knowledge brokering strategy ('collaboration') was initially selected to be employed in this case, in practice the role of the knowledge broker proved to be dynamic, employing a range of strategies. The initial 'match-making' strategy successfully opened up a route of communication between the researchers and policy makers and helped the researchers locate their intended tool development exercise in a relevant policy area - especially considering the researchers reluctance to interact with their own contacts within the Commission. However, this relatively simple strategy was not sufficient to embed the tool development process in the policy area and the researchers struggled to make progress for several months. Crucially this led to a missed opportunity to jointly frame the tool development process with the policy makers: In theory one of the principal tasks of the knowledge broker is to help facilitate the iterative process of clarifying the policy questions - what is the policy maker seeking to answer - so that they are acceptable to policy makers and answerable by researchers (Campbell et al. 2011).

In the next 'Scoping and Planning Phase' the knowledge broker switched to a more elaborate strategy, namely 'engaging'. In particular, the knowledge broker helped the researchers to frame their discussion in a way that was intended to actively involve policy makers in the substantive aspects of the problem on a 'as needed basis' (see Michaels 2009, p. 997). In part this strategy was not selected by the knowledge broker but dictated by the desire of the researchers to gather specific technical feedback from the policy makers. In this way the researchers limited the scope and extent of the input by policy makers in the tool development exercise (e.g. by excluding certain requests made to incorporate additional aspects to the model) by framing the discussion on their (researcher) terms. The strategy itself was relatively successful in eliciting the information required from policy makers: While the researchers did not get all the specific technical feedback that they sought from the policy makers in Meeting 1, it did set the groundwork for the smaller more targeted meetings (e.g. Meetings 3 and 4). Although the researchers were pleased with the high level of policy maker participation in Meeting 1, this was not in practice that helpful in obtaining the technical input they sought to proceed with the model development exercise.

The more elaborate strategy, namely 'collaboration', employed during the 'Scoping and Planning Phase' was intended to help the researchers and policy makers to gain an understanding of each others expectations and to build trust. The group mapping exercise in particular sought to elicit an open and equal discussion of relevant research and policy relevant questions and to start matching these up so that the researchers and policy makers jointly framed the process of interaction and negotiated the substance to be addressed (see Michaels 2009, p. 997). In practice these the two strategies of 'engaging' (see above) and 'collaboration' employed in this meeting sat side by side rather uneasily. This was perhaps not surprising as in 'engaging' the researchers framed the discussion while in 'collaboration' both parties were to jointly frame the discussion. The group mapping exercise led to an interesting discussion between the policy makers and researchers in which their understanding of each other's expectations did appear to grow. However, neither this exercise alone, nor the whole knowledge brokering process, was enough to form a working relationship between the researchers and policy 
makers based on trust, for instance where weakness could be displayed. This in part led to some of the delays observed between the meetings as concerns from the researchers about eroding their credibility in the eyes of the policy makers led to further improve and substantiate what was presented. In the end, this exercise did not even elicit the type of information that the researchers found useful: The researchers claimed that the policy makers mostly identified open ended 'blue skies' type of policy questions which the researchers found hard to match with their - relatively specific - technical activities. Furthermore, requests for more active input to the tool development process were not taken up by the policy makers who appeared reluctant to commit significant resources to the tool development exercise. In the end, this more elaborate knowledge brokering strategy of 'collaboration' was dropped.

\section{2) Are these the same strategies anticipated in the knowledge brokering literature?}

In general, the medium-level knowledge brokering strategies (i.e. 'match making' and 'engaging') were more successful than the higher-level strategy of 'collaboration' that was anticipated from an analysis of the literature on knowledge brokering. The reasons for this apparent discrepancy are discussed below. Furthermore, while in this case Michaels' typology was used to select one theoretically informed strategy (i.e. 'collaboration'), in practice a range of strategies proved more appropriate. Michaels (2009, p. 1008) argues that the decision-aiding frameworks make it possible to select an appropriate knowledge brokering strategy for each of the different policy problems or setting identified in the frameworks, she goes on to state that ' $[t]$ he match between strategies and problem and strategies under no circumstances is going to be exact': Both the categories of strategies as well as the types of policy problems and policy scenarios overlap. Ward et al. (2009) also argue that it is not always feasible to use only one type of strategy in isolation.

\section{3) What are the barriers to applying a knowledge brokering approach in the tool development process?}

A number of barriers to applying the knowledge brokering process were observed in practice. First, the knowledge brokering strategy was selected by the knowledge broker based on an assessment of the contextual characteristics of the case. In hindsight this may have differed from how the policy makers and researchers perceived the case. Indeed, Michaels (2009) warns that there is a tendency for actors to pull towards problem and policy characteristics that they feel most comfortable in and that fit their institutional framing. For example, although the policy problem was perceived by the knowledge broker as unstructured (as neither the goals or the means by which to achieve them were agreed), both the researchers and policy makers appeared to frame it as a well structured and technical problem: what was required was more, and more detailed, research on the possible climate change impacts. Similarly, while the knowledge brokering perceived the policy problem as occupying the unordered complex domain of what can be known, by attempting to apply an integrated computer modelling tool, both the researchers and policy makers implied that the cause and effect relationships are knowable (given enough research) though a systems approach. Crucially, these perceived problem characteristics point to a lower level of knowledge brokering strategy. This may have contributed to the reluctance of both policy makers and researchers to invest more time and resources in the knowledge brokering process than was felt necessary for the task in hand - as they perceived it. 
Another important factor in this case was that it was 'knowledge driven' (i.e. initiated mainly by the researchers) and not 'policy driven' (i.e. initiated by the policy makers). While the policy making process is often depicted as starting with a policy problem in search of a solution - via the input of scientific expertise, in reality, policy making is often far more chaotic. It is also possible for a policy solution to be in search of a policy problem (Kingdon 2010). In this case, the starting point of the knowledge brokering process was scientific expertise, in the form of tool development, in search of a policy problem. In such knowledge driven models of knowledge use Contandriopoulus et al. (2010) warns us that the costs of knowledge production are mainly covered by the producers. This contrasts with more demand driven models where costs of production are shared between users and producers (ibid). In this case, therefore, it is perhaps not surprising that the policy makers and researchers were not prepared to invest more time and resources in a truly collaborative process. Sufficient time and resources for conducting the knowledge brokering process are seen in the literature as critical to its success (Sheate and Partidario 2010; Ward et al. 2009; Michaels 2009). However, it may not necessarily be enough to simply increase resources: the distribution of resources is also important. In addition, the actors must be free to use these resources. At times the policy makers in this case appeared to be reluctant to more actively participate in the tool development process due to political constraints of policy making, which can inhibit the serious and critical exploration of policy options (Bäcklund 2009).

A third barrier to applying a knowledge brokering approach to the tool development process was the apparent reluctance, at times, of the researchers to interact with policy makers at all. This was partly a result of the researchers' concern to maintain credibility and trust within DG Agriculture, which had been built up over many years and on which the researchers would continue to rely on in future. Therefore it was difficult at times to encourage the researchers to move beyond a 'business as usual' approach in their research. They often appeared to continue their tool development process relatively independently of the policy makers input. At times the desired role of the policy makers appeared more to legitimize the tool development process than to input into it. To some extent this was due to the knowledge driven nature of the case and the use of predetermined existing models, which could only respond to certain policy questions and demands. As one researcher argued, 'there is a strong conflict between the flexible way users would like to get....information and the inflexibility of the complex modelling systems'. In other words, integrated modeling tools have well-defined areas, or set of policy questions, that they can answer and beyond which they require substantial amount of work taking time and resources that are often not available. While involving policy makers in the development of the models can help tailor the tools to specific requirements of a policy maker within these well-defined areas, it can do little to alter this conflict more fundamentally.

It should also be noted that the policy makers also appeared reluctant at times to engage with the researchers - especially over requests for active input into specific documents and their emphasis that they were participating as individuals and not committing DG agriculture either to the tool developing exercise nor - more implicitly - to using the resulting model. Therefore, the policy makers also had a 'business as usual' approach, which may have acted as a barrier to greater interaction with the researchers. Collaboration and co-production of knowledge is at odds with the institutional norms for information gathering in the Commission (and policy making more widely). For example, as mentioned above, various organisations (such as the JRC) have been set up within the Commission to facilitate the use of model. 


\section{5) Conclusions}

This article aims to apply the knowledge brokering approach to contextualise the development of an integrated computer modelling tool in a real world policy context. According to arguments put forward in the tool development literature (see above), the more involvement policy makers have in the modelling process, the greater the ultimate impact of the exercise in policy making. This article reports only on the first of two stages of tool development and it is not yet possible to say if, and if so how, the integrated tool will be used by policy makers in future. Besides this, the counterfactual (what would have happened if the knowledge brokering approach had not been applied) is hard to establish. However, returning to the three more immediate research questions posed at the beginning of this article (see above) leads to several conclusions which have implications for both the literature on knowledge brokering and tool development.

First, while the mainly theoretical literature on knowledge brokering is useful in identifying and articulating different knowledge brokering strategies and techniques, this article has demonstrated the messy and non-linear nature of knowledge brokering in practice. Contextual factors such as the policy problems and scenario, while narrowly defined in the literature, in practice overlap and can be perceived differently by various actors. Knowledge brokering strategies also overlap and are not always (if at all) used in isolation. Added to this, while some of the knowledge brokering literature implies that the knowledge brokering process starts with a policy problem that can be addressed given the 'right' scientific information (e.g. Micheals 2009; Campbell et al 2011), in practice the knowledge brokering process can be knowledge driven. In this way, our findings provide support for those of Ward et al. (2011) which emphasise the dynamic nature of the knowledge brokering process. Ward et al. (2011) define five key components of knowledge exchange (problem, context, knowledge, activities, and use) that can all be at play at any one time and (crucially) do not occur in any set order. A greater appreciation and understanding of this fluid and some what chaotic nature of the knowledge brokering process would help better align the theory and practice of knowledge brokering.

Second, evaluating knowledge brokering strategies and techniques is not straightforward and as yet there is little guidance on what types of knowledge brokering outcomes can and should be measured (e.g. increased evidence use, relationships and interaction between researchers and policy makers) (Ward et al. 2009) (but see Sheate and Partidário 2010, p. 280-1). This article opted for a processorientated approach to evaluating the knowledge brokering process focusing on matching the context in which the knowledge brokering takes place to the planning and implementing of specific knowledge brokering activities. However, while the article to some extent finds a mis-match between the theoretically informed knowledge brokering strategy and the strategies that were more successful in practice, this does not necessarily mean that the knowledge brokering process was a failure. A number of barriers to a more elaborate knowledge brokering strategy have been identified but it is also important to consider what the knowledge brokering approach did achieve as well as what it did not. The exercise fell short of co-producing knowledge, however, it did open up access for the researchers to the 'right' policy makers at critical junctures of the tool development process. This led to a two-way flow of information which allowed the researchers to get specific input from policy makers on critical parameters of the model development and tailor their tool development towards a real world policy context. At the same time the knowledge brokering process also led to the establishment of a small group of specialised policy makers within DG Agriculture who took an interest and engaged in the 
development of this integrated tool and with whom the researchers can interact in future. Unfortunately, it is less clear what the policy makers felt was achieved by the knowledge brokerage exercise since the author was not privy to their internal correspondence and discussions in the same way as for the researchers.

Finally, the general perception discussed earlier that there is a poor uptake of computer modelling tools in policy decisions and a need to 'bridge the gap' between researchers and policy makers, in the EU agricultural policy area at least, appears to be questionable. The science policy interface may not always characterised by an absence of information for policy makers and even less a lack of available routes to obtain it: Certain EU policy areas (such as agriculture, climate change and the environment) have more tradition than others in using modelling tools (Nilsson et al. 2008). There are multiple sources of information and tools available to the DG Agriculture, not least from within the Commission's own institutions such as the Joint Research Centre. Furthermore, since tool choice is shaped by institutional norms and routines (Nilsson et al. 2008), path dependency may tend towards the use of these in-house, or at least tried and tested, tools and experts. Therefore, in this case, it is at least questionable whether the gap between researchers and policy makers is in practice characterised as one of a problem of tool design and communication - as is often portrayed in the tool development literature. Is it not rather a problem of competition between different researchers and research organisations to have 'their' tools used in the policy making process? Sterk et al (2009b, p.439) mentions the role of 'expectation management' by researchers as a kind of marketing strategy 'which raises interest from potential users, .... balances expectations and ......allows for dovetailing of the modelling work with the specific interests and questions of the policy-makers'. This rather different understanding of the science policy interface does not negate the application of a knowledge brokering approach. However, it does shed a new light on the expectations and motivations of both the policy maker and the researchers which could be better articulated and explored in the knowledge brokerage literature in future.

\section{Acknowledgements}

I would like to thank the team of LIAISE researchers and policy makers within DG Agriculture who took part in the process described in this article. I would also like to thank John Turnpenny, Andrew Jordan, and Tarja Söderman as well as two anonymous referees for their constructive comments on an earlier draft. This paper was written with the financial support of the Linking Impact Assessment Instruments with Sustainability Expertise (LIAISE) Network of Excellence financed under the European Commission's Seventh Framework Programme (Project Number 243826). In addition, I gratefully acknowledge the support of a Post-Doctoral Fellowship from the University of Pretoria, South Africa.

\section{Notes}

1. The models were: FFSIM, CAPRI, INTEGRATOR, SIMPLACE. SIMPLACE is a crop growth model that is suited to do crop yield calculations at large scales. CAPRI is a comparative static partial equilibrium model for the agricultural sector and trade policies from global to regional and farm type scale, focusing on EU27 level. FFSIM is a generic bio-economic farm model that has been developed to quantify the integrated agricultural, environmental and economic responses of major farm types across the EU to new policies and agrotechnologies. INTEGRATOR is an environmental agricultural model, which can calculate 
Nitrogen and greenhouse gas emissions from housing and manure storage systems, agricultural soils, non-agricultural soils and surface waters at EU 27 level.

2. www.liaise-noe.eu/

\section{References}

AEA (2007) Adaptation to climate change in the agricultural sector. Report for the European Commission - AGRI-2006-G4-05. http://ec.europa.eu/agriculture/analysis/external/climate/final en.pdf Accessed 1/10/12

Bäcklund, A.K., Bousset, J.P., Brogaard, S., Macombe, S., Taverne, M., van Ittersum, M.K., (2010) Science - policy interfaces in impact assessment procedures. In: Brouwer, F., van Ittersum, M.K. (Eds.), Environmental and agricultural modelling: integrated approaches for policy impact assessment. Springer, Dordrecht, pp. 275-294.

Bäcklund, A.K. (2009) Impact assessment in the European commission - a system with multiple objectives. Environmental Science and Policy, 12(8), 1077-1087.

Campbell, D., Braedon, D., Moore, G., and Frew, D. (2011) Evidence check: knowledge brokering to commission research reviews for policy. Evidence and Policy, 7(1), 97-107.

Contandriopoulus, D., Lemire, M., Denis, J.L., and Tremblay, E. (2010) Knowledge exchange processes in organizations and policy arenas: a narrative systematic review of the literature. The Milbank Quarterly, 88(4), 444-483.

Daugbjerg, C. and Swinbank, A. (2009) Ideational Change in the WTO and its Impacts on EU Agricultural Policy Institutional and the CAP'. Journal of European Integration, 31, 311-327.

Donatelli, M. et al., (2012) Assessing agriculture vulnerabilities for the design of effective measures for adaptation to climate change. Report on the AVEMAC Study for the European Commission. http://ec.europa.eu/agriculture/analysis/external/avemac/index en.htm (Accessed 28/06/13)

European Commission (2009a) White paper - Adapting to climate change: Towards a European framework for action. (COM (2009) 147).

European Commission (2009b) Adapting to climate change: the challenge for European agriculture and rural areas. (SEC (2009) 417).

Iglesias, A., Garrote, L., Quiroga, S., Moneo, M. (2009) Impacts of climate change in agriculture in Europe. PESETA-Agriculture study, JRC - IPTS.

van Ittersum, M.K., Ewert, F., Heckelei, T. et al., (2008) Integrated assessment of agricultural systems - A component-based framework for the European Union (SEAMLESS). Agricultural Systems 96, 150-165.

van Kammen, J., de Savigny, D., Sewankambo, N. (2006) Using knowledge brokering to promote evidence-based policy-making: the need for support structures. Bulletin of the World Organization, 84 (8), 608-612.

Kingdon, J. (2010) Agendas, Alternatives and public Policies. Second edition. Longman: New York.

Kurtz, C.F., Snowden, D.J., (2003) The new dynamics of strategy: sense-making in a complex and complicated world. IBM Systems Journal 42(3), 462-483.

LIAISE (no date) About LIAISE. http://www.liaise-noe.eu/content/our-mission-interdisciplinarycommunity-ia-researchers-and-practitioners Accessed 30 December 2013.

Lindquist, E.A., (2001) Discerning policy influence: framework for a strategic evaluation of IDRCSupported research. 
Michaels, S. (2009) Matching knowledge brokering strategies to environmental policy problems and settings. Environmental Science and Policy 12, 994-1011.

Nilsson, M. Jordan, A., Turnpenny, J., Hertin, J. Nykvist, B. and Russel, D. (2008) The use and non-use of policy approasal tools in public policy making: an analysis of three European countris and the European Union. Policy Science 41, 335-355.

Sheate, W. and Partidario, M.R. (2010) Strategic approaches and assessment techniques-Potential for knowledge brokerage towards sustainability. Environmental Impact Assessment Review 30, 278-288.

Sterk, B. van Ittersum, M.K., Leeuwis, C. (2011) How, when, and for what reasons does land use modelling contribute to societal problem solving? Environmental Modelling and Software 26, 310-316.

Sterk, B., Leeuwis, C., van Ittersum, M.K. (2009a) Land use models in complex societal problem solving: Plug and play or networking? Environmental Modelling and Software 24, 165-172.

Sterk,B., Carberry, P., Leeuwisc, C., van Ittersumd, M., Howdene, M., Meinkef,H., van Keuleng, H., and Rossingh, W. (2009b) The interface between land use systems research and policy: Multiple arrangements and leverages. Land Use Policy 26, 434-442.

Turnhout, E., Hisschemoller, M., Eijsackers, H., (2007) Ecological indicators: between the two fires of science and policy. Ecological Indicators 7(2), 215-228.

Ward, V., Smith, S., House, A., Hamer, S. (2011) Exploring knowledge exchange: A useful framework for practice and policy. Social Science and Medicine, 74(3), 297-304.

Ward, V., House, A., House, S. (2009) Knowledge brokering: the missing link in the evidence to action chain? Evidence and Policy 5(3), pp. 267-79. 